\title{
Importance of dietary consultation after cholecystectomy: pre- and post-cholecystectomy nutritional status, dietary habits and anthropometric measures of patients
}

\author{
B. Ozyel ${ }^{1,2}$ and N. Malyali ${ }^{1}$ \\ ${ }^{1}$ Nutrition and Dietetics Department, European University of Lefke, Lefke, Northern Cyprus, TR-10, Mersin, Turkey \\ and ${ }^{2}$ Vocational School of Health Services, European University of Lefke, Lefke, Northern Cyprus, TR-10, Mersin, Turkey
}

Gallstone disease has become an emerging public health problem with its increasing prevalence in most developing and developed countries leading to high healthcare costs ${ }^{(1)}$. Obesity, diabetes, physical activity, gender, age, number of pregnancies, lifestyle and dietary habits are among the causes of gallstones. Currently, cholecystectomy is acknowledged as the gold standard option in gallstone disease treatment ${ }^{(2)}$. Although risk factors for gallstone formation have been reported in numerous studies ${ }^{(3)}$, the literature considering the necessity of a specific diet for patients submitted to cholecystectomy is very scarce. Therefore, this study was performed to assess pre- and post-cholecystectomy nutritional status, dietary habits and anthropometric measures of patients.

Subjects were chosen among the patients admitted to a state hospital between January 2015 and April 2017 in the west region of North Cyprus. After reviewing medical records, a total of 35 subjects (78\% female) who were submitted to cholecystectomy due to cholelithiasis or cholecystitis were included. Pre-cholecystectomy anthropometric measures (height and weight) were obtained by retrospective medical review. For this study, we contacted all 35 patients by e-mail and followed up non-responders with telephone to arrange an appointment in May 2017 for post-cholecystectomy anthropometric measurements and conduction of face-to-face dietary assessment. Dietary assessment data for both pre- and post-cholecystectomy were collected by applying questionnaire for general knowledge and dietary habits, food frequency questionnaire and twenty-four-hour dietary recall.

According to our retrospective medical review and statements of subjects, none of them received any dietary consultation or dietary restrictions from any health professionals pre- or post-cholecystectomy $(\mathrm{n}=35)$. Subjects had a mean BMI of $29.60\left(\mathrm{SD} 6.14 \mathrm{~kg} / \mathrm{m}^{2}\right)$ prior to cholecystectomy falling into pre-obesity class according to World Health Organization (WHO) classification. There was no weight lost observed in any of the subjects after cholecystectomy. Nevertheless, there was a significant increase in the mean BMI of subjects after cholecystectomy $(\mathrm{n}=35, P<0.05)$ (Table $1 \mathrm{~A})$. Classification of BMI values revealed that there were changes in nutritional status of subjects after cholecystectomy (Table 1B). Dietary assessments indicated that there were no significant alterations in fat consumption patterns of subjects in their diets after cholecystectomy $(P>0.05)$. On the other hand, an increase was observed in

Table 1. [A] Pre- and post-cholecystectomy body weight and BMI values. [B] Classification of BMI values and changes in nutritional status after cholecystectomy. A.

\begin{tabular}{|c|c|c|c|c|c|c|}
\hline \multicolumn{7}{|l|}{ A. } \\
\hline & \multirow[b]{2}{*}{$\mathrm{n}$} & \multicolumn{2}{|c|}{ Pre-cholecystectmy } & \multicolumn{2}{|c|}{ Post-cholecystectomy } & \multirow[b]{2}{*}{$P$-value* } \\
\hline & & Mean & SD & Mean & SD & \\
\hline $\begin{array}{l}\text { Body weight }(\mathrm{kg}) \\
\text { BMI }\left(\mathrm{kg} / \mathrm{m}^{2}\right)\end{array}$ & $\begin{array}{l}35 \\
35\end{array}$ & $\begin{array}{l}78.69 \\
29.60\end{array}$ & $\begin{array}{l}16.57 \\
6.14\end{array}$ & $\begin{array}{l}81.90 \\
30.77\end{array}$ & $\begin{array}{l}16.98 \\
6.15\end{array}$ & $\begin{array}{l}<0.05 \\
<0.05\end{array}$ \\
\hline
\end{tabular}

* data were compared with paired samples t-test

B.

\begin{tabular}{|c|c|c|c|c|c|c|c|c|}
\hline & & & Post- & holecystecton & y nutritio & lal status & & \\
\hline & & & Normal weight & Pre-obesity & $\begin{array}{l}\text { Obesity } \\
\text { class I }\end{array}$ & $\begin{array}{l}\text { Obesity } \\
\text { class II }\end{array}$ & $\begin{array}{l}\text { Obesity } \\
\text { class III }\end{array}$ & Total (Pre-cholecystectomy) \\
\hline Post-cholecystectomy nutritional status & Normal weight & $\mathrm{n}$ & 5 & 5 & - & - & - & 10 \\
\hline & & $\%$ & 50 & 50 & - & - & - & 100 \\
\hline & Pre-obesity & $\mathrm{n}$ & - & 6 & 4 & - & - & 10 \\
\hline & & $\%$ & - & 60 & 40 & - & - & 100 \\
\hline & Obesity & $\mathrm{n}$ & - & - & 9 & - & - & 9 \\
\hline & class I & $\%$ & - & - & 100 & - & - & 100 \\
\hline & Obesity & $\mathrm{n}$ & - & - & - & 3 & 1 & 4 \\
\hline & class II & $\%$ & - & - & - & 75 & 25 & 100 \\
\hline & Obesity & $\mathrm{n}$ & - & - & - & - & 2 & 2 \\
\hline & class III & $\%$ & - & - & - & - & 100 & 100 \\
\hline & Total (Pre-cholecystectomy) & $\mathrm{n}$ & 5 & 11 & 13 & 3 & 3 & 35 \\
\hline & & $\%$ & 14 & 31 & 37 & 9 & 9 & 100 \\
\hline
\end{tabular}

white bread, pasta, potato and fresh fruit consumption whereas water consumption was reduced after cholecystectomy $(P<0.05)$.

The results from the study would indicate that the subjects experienced weight management problems both pre- and postcholecystectomy. This might be associated with insufficient dietary consultation. Although there is no consensus on a specific diet plan after cholecystectomy, some dietary advice would help subjects to maintain their body weights and lower the risk for chronic diseases.

1. Stinton LM, Shaffer EA (2012) Gut Liver 6, 172-187.

2. Bagla P, Sarria JC, Riall TS (2016) Curr Opin Infect Dis 29, 508-513.

3. Pak M, Lindseth G (2016) Gastroenterol Nurs 39. 